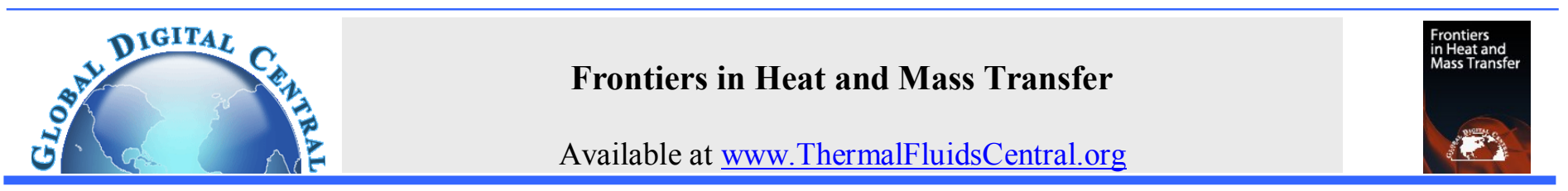

\title{
NUMERICAL STUDY OF FIN-TUBE TYPE HEAT EXCHANGER WITH
}

\section{DELTA WINGLETS}

\author{
Divyprakash C. Pal, Abhik Majumder* \\ Department of Mechanical Engineering, National Institute of Technology Agartala, Tripura, 799046, India
}

\begin{abstract}
In this present work heat transfer characteristics, thermal performance and pressure drop are studied numerically for a finned-tube bank heat exchanger with Delta Winglet Vortex Generator (DWVG) on the fin at different angle of attack $(\alpha)$. The thermo-fluid is studied by varying $\alpha$ at $15^{\circ}, 25^{\circ}, 30^{\circ}$ and $35^{\circ}$. The base length (l $\mathrm{l}_{\mathrm{DW}}$ ) of the winglet also varied from $20 \mathrm{~mm}$ to $35 \mathrm{~mm}$. The heat transfer coefficient and pressure drop increased in all the cases with increase in Reynolds number. However, significant increase in heat transfer of about $23.92 \%$ was observed for $\alpha$ at $35^{\circ}$ when compared with plain fin heat-exchanger.
\end{abstract}

Keywords: fin-and-tube heat exchanger, delta winglet vortex generator, heat transfer enhancement.

\section{INTRODUCTION}

Plate-fin and tube-fin are generally compact heat exchanger, having high heat transfer surface per unit volume. Such heat exchangers are widely used in air-conditioning, refrigeration systems, transportation, petrochemical, food processing, residential HVAC and other industries. The basic tube-fin design consists of a stack of closely spaced fins through which tubes have been inserted. Generally, the application of these heat exchangers, involves a temperature or phase change of a fluid, resulting in the absorption or rejection of energy in the form of heat. Air side thermal resistance is critical part of heat transfer process due to the thermo-physical properties of air, and is usually dominant, because heat transfer coefficients are fundamentally lower for the gas side than for liquid or two phase flow. During the past years lot of research has been done on fins with vortex generators (VGs) to improve heat transfer at the modest cost of pressure drop increment.

Schubauer and Spangenberg (1960), presented a review of the early use of streamwise vortices in boundary layer control, who also measured the effects of a number of mixing and vortex generating surface elements on boundary layer development. Sedney (1973), presented a thorough review of the effects of the small protuberances on boundary layer flows. Edwards and Alker (1974), after comparing delta winglets and cubes placed on flat surfaces, found out that the delta winglets provided higher overall heat transfer enhancement compared to cubes. Katoaka et al. (1977), experimentally investigated the effect of vortices related to its flow direction which shows that the heat transfer is locally enhanced in the region where two neighboring vortices impose a flow toward the surface and the heat transfer locally decreases where the vortices impose a flow away from the surface. Eibeck and Eaton (1987), experimented on longitudinal vortices embedded in turbulent boundary layer and concluded that heat transfer is highly enhanced by longitudinal vortices. Mehta and Bradshaw (1988), observed and reported that the vortex generators produced two types of flow patterns by changing their angle of attack; the flow between Vortices is directed either away from the wall, common-flow-up, or toward the wall, common-flow-down. Pauley and Eaton (1988), observed heat transfer enhancement by increasing the spacing of vortex generators in the common-flow-up and reported that in the case of increasing the spacing of vortex generators, the commonflow-up pair also has the same peak and minimum heat transfer coefficient as observed for the common-flow-down pair. Fiebig et al. (1991), carried out a comparative study between triangular and rectangular vortex generators and found out that heat transfer enhancement per unit vortex generator area was highest for delta wings followed by delta winglets and rectangular winglets. Biswas and Chattopadhyay (1992), studied effect of a punched hole, beneath the wing-type vortex generator, on heat transfer and skin friction characteristics and found out that the Nusselt number showed and increment of $34 \%$ at an attack angle of $26^{\circ}$. Tigglebeck et al. (1994), carried out by a thorough analysis of the effect of the geometry of the vortex generator, their result showed that the delta winglet pairs present better heat transfer results.

Chen et al. (2000), studied heat transfer enhancement of a finned oval tube with staggered punched longitudinal vortex generators and concluded that winglets in staggered arrangement bring larger heat transfer enhancement than in in-line arrangement since the longitudinal vortices from the former arrangement influence a larger area and intensify the fluid motion normal to the flow direction. Torii et al (2002), performed and experimental study on the fin and tube heat exchanger in staggered arrangement of tubes as well as in-line arrangement of the tubes with delta winglet vortex generator in various configurations. The staggered arrangement of tubes configuration caused significant separation delay, reduced form drag, and removed the zone of poor heat transfer from the near-wake of the tubes.Wang et al. (2002), visualized the flow structure for enlarged plain fin-and-tube heat exchanger with annular and delta winglet vortex generators using a dye-injection technique. Torii et al. (2003), investigated the heat transfer and pressure loss penalty for various numbers of transverse rows in staggered finnedtube bundles with a single transverse row of the winglet pairs beside the front row of the tube bundles, since staggered arrangement provided a better performance than in-line arrangement of tubes. 
Tiwariet al. (2003) performed studies on oval type tube geometry for improving the overall performance of the fin and tube heat exchangers. He made a three-dimensional study of laminar flow and heat transfer with built-in oval tubes and delta winglets. A comparison of heat transfer for the cases of one, two and three winglet pairs (all in commonflow-down configuration) confirm that the addition of each extra winglet pair causes further enhancement of heat transfer. The heat transfer for the two rows was the highest and increased by $20-35 \%$ while for three-row tube bundle, the heat transfer was augmented by $10-30 \%$. Leu et al. (2004), studied the heat transfer and flow in the plate-fin and tube heat exchangers, numerically as well as experimentally with inclined block shape vortex generators mounted behind the tubes. Pesteeiet al. (2005) performed an exhaustive experimental work was carried out to determine the best position of the delta winglet pairs for a given aspect ratio. While carrying out the experiment amongst all the cases, the maximum value for local heat transfer coefficient was observed at the winglet position $\Delta \mathrm{x}$ $=0.5 \mathrm{D}, \Delta \mathrm{y}=0.5 \mathrm{D}$ which gave an increase of average Nusselt number of $46.64 \%$ and increase in pressure drop of $18.07 \%$. Kwak et al. (2005), performed an experiment on heat transfer enhancement and pressure loss penalty caused by a single row of winglets built in the first transverse row of tubes, and comparing it between "common flow up" ("toe-out") and "common flow down" ("toe-in") winglet configurations. The results on experimenting were that the heat transfer enhancement for two rows of winglets became slightly higher by $6-15 \%$ in a whole range of Reynolds number than for a single front row of winglets. The corresponding increases for the in-line arrangement in heat transfer and pressure loss were 7-9\% and 3-9\%, respectively.

Allison and Dally (2007), performed an experiment analyzing the effects of delta-winglet vortex generators on the performance of a fin and tube radiator. The winglets were arranged in flow-up configuration, and placed directly upstream of the tube. They chose water Reynolds number flows similar to those of the air Reynolds numbers for their prototype evaluation. The goodness factor, jf-factor, increased with the increase of the Reynolds number and that the maximum value is 0.87.This experiment highlights the advantage of delta-winglet vortex generator and the overall performance improvement of the heat exchanger. Joardar and Jacobi (2007), also numerically investigated the flow and heat transfer enhancement using an array of VGs in a fin-and-tube exchanger with common-flow-up arrangement. They observed that the impingement of winglet redirected flow on the downstream tube is an important heat transfer augmentation mechanism for the inline-tube geometry. Yang et al. (2008), numerically investigated the effects produced by common-flow-up vortex generators on heat transfer characteristics and fluid flow. The effects produced by this kind of arrangement of vortex generator, in case of flow field, was that the boundary layer is thinned in the region where the secondary flow is directed toward the wall and thickened where it is directed away from the wall. They concluded that such an effect was evident because, the interaction between the vortices becomes very strong while the interaction among the vortices and the boundary layers becomes very weak. As the common-flow-up pair develops, their lifting effect from the bottom wall increases more and more.

Joardar and Jacobi (2008), experimentally found that the air-side heat transfer coefficient increased from $16.5 \%$ to $44 \%$ for the single row winglet arrangement with an increase in pressure drop of less than $12 \%$.He et al. (2010), proposed a VG array deployed in a V-like configuration by imitating the formations of animals' group movement and their experiments showed that this configuration only caused very low pressure drop penalty. Wu et al. (2011) numerically simulated a different kind of arrangement of the tubes, with two rows of tubes in different diameter. The performance of a conventional fin-tube surface with plain fin and two rows of tubes in the same diameter was denoted as "baseline" or case A and, with two rows of tubes in different diameters as case B. Compared with the baseline, the average Nusselt number decreased $5.9-12.7 \%$ for case $A$, and increased $5.7-12.7 \%$ for case B, while case B had lower pressure drop in the same Nusselt number. He et al. (2012) numerically investigated the potential of punched winglet type vortex generator (VG) arrays used to enhance airside heat-transfer performance of finned tube heat exchanger. The numerical results show that for the punched VG cases, the effectiveness of the main vortex to the heat transfer enhancement is not fully dominant while the "corner vortex" also shows significant effect on the heat transfer performance. Both heat transfer coefficient and pressure drop increase with the increase of attack angle for the side arrangements. Sinha et al. (2013), performed a numerical investigation taking in account five different strategic placement of two rows of $\mathrm{VG}$ was performed Common-flow up in series (CFU-CFU), common-flow down in series (CFD-CFD), combined (CFD-CFU), inline rows of winglet (IRW) and staggered rows of winglet (SRW), were considered. CFU-CFU clearly performed best at high Re while the SRW performed comparatively as well as CFU-CFU at a low value of $\mathrm{Re}$, i.e. at $\mathrm{Re}=250$. Delac et al. (2014)presented a numerical analysis of heat transfer and pressure drop using vortex generators in fin and flat tube heat exchanger. Using set pairs of rectangular winglet in downstream orientation they studied the effect of impact angles of $5^{\circ}, 10^{\circ}$ and $20^{\circ}$ as well as winglet height. The results showed that pressure drop increases for higher impact angle and with winglet height.

So far there has been very few reported work on variation of parameters related to the delta winglet vortex generators(DWVG), specifically, angle of attack, and the base length of the delta winglet for non-mixing 'common-flow up' configuration of staggered fin tube heat exchanger. And no work has been reported on three rows of DWVG's in staggered fin tube heat exchanger. The variation of parameters as stated are of great importance in regards to improvement of overall performance of the fin-tube type heat exchanger. In this work, numerical study of fin-tube heat exchanger with DWVGs arranged in common-flow up arrangement has been done. The parameters which are varied are the angle of attack $(\alpha)$, spanwise distance between the trailing edge of the winglets and the tubes (s), followed by variation in base length of the DWVG. Its effect on heat transfer characteristics and pressure drop have been reported. The $\mathrm{j}$-factor and f-factor have been used to evaluate the performance of the fin and tube heat exchanger.

\section{PROCEDURE AND METHODS}

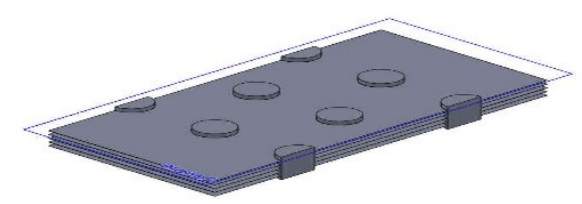

Fig. 1 Schematic view of plain fin-tube heat exchanger model.

To address the above objective a numerical model is chosen, Fig. 1 shows schematic diagram of core region of plain fin and tube heat exchanger with three rows of the circular tubes with staggered arrangements. The tube is of $30 \mathrm{~mm}$ outer diameter and flat plate of $\left(\mathrm{F}_{t}\right) 0.3 \mathrm{~mm}$ thickness, respectively. The fin pitch $(\mathrm{H})$ is $5.6 \mathrm{~mm}$. Due to symmetry, as seen in Fig. 2, the computational domain is given symmetry on the left and the right sides along the flow direction and in Fig. 4 the two neighboring fins centric surface are taken as the upper and lower boundaries of the computational domain. The actual computational domain is extended 20 times of the fin spacing from the entrance to ensure a uniform velocity distribution. At the exit, 20 times of fin spacing is also extended downstream to avoid recirculation, (Chu et al., 2009).

The length of the fin is $300 \mathrm{~mm}$, the span-wise and stream-wise pitches are $75 \mathrm{~mm}$, while, the base length of winglet $\left(l_{\mathrm{DW}}\right)$ is $30 \mathrm{~mm}$. The delta winglet height $(\mathrm{h})$ is $5 \mathrm{~mm}$ and a span-wise gap between the trailing edge of winglet and the surface of tube (s) is $9 \mathrm{~mm}$. The angle $\alpha$ is the angle between flow direction and central axis of the DWVG as shown. Whereas, the central angle $(\beta)$ is measured between P and Q. In the 
present work $\alpha$ and lDw are chosen as the parameter. The value of $\alpha$ is varied from $15^{\circ}$ to $35^{\circ}$ with an increment of $5^{\circ}$. The value of $\beta$ decreases as $\alpha$ increase. Furthermore, the value of $l_{\mathrm{DW}}$ is also varied from $20 \mathrm{~mm}$ to $35 \mathrm{~mm}$ to see the effects of base winglet length on heat transfer keeping $\alpha$ constant at $30^{\circ}$. The DWVG are placed perpendicular to the fin in single surface, for all the three rows of the tubes. Fig. 3 shows the geometric details of delta winglets and delta winglet arrangement.

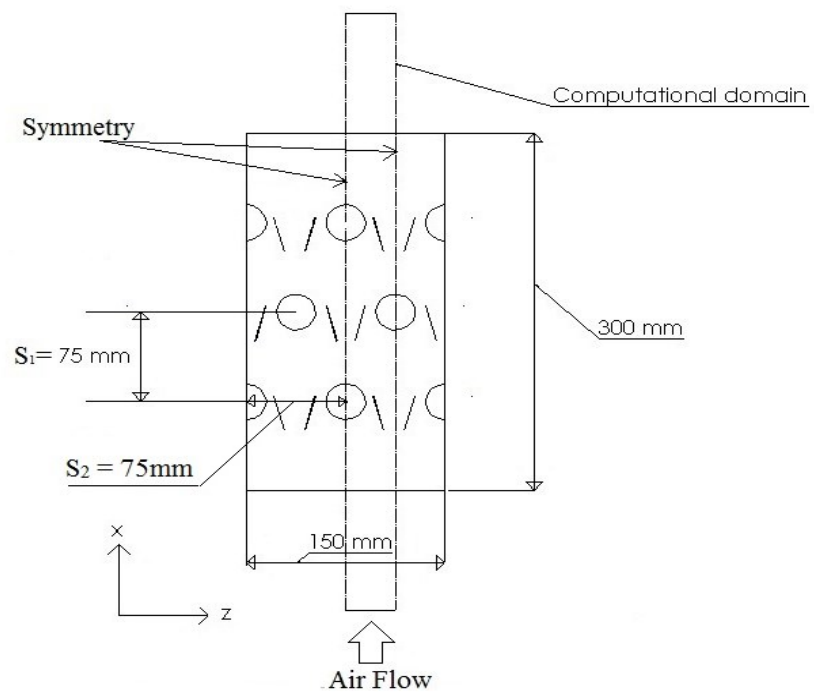

Fig. 2 Top view of computational domain

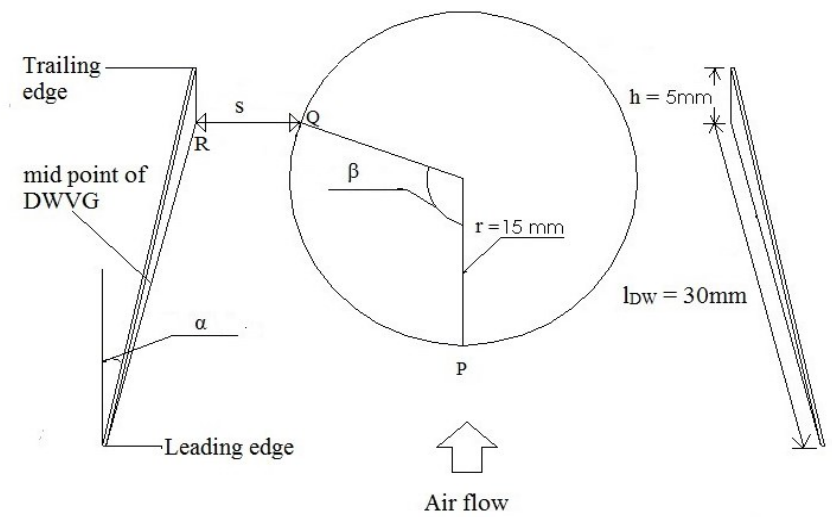

Fig. 3 Geometric details of delta winglets and its arrangement.

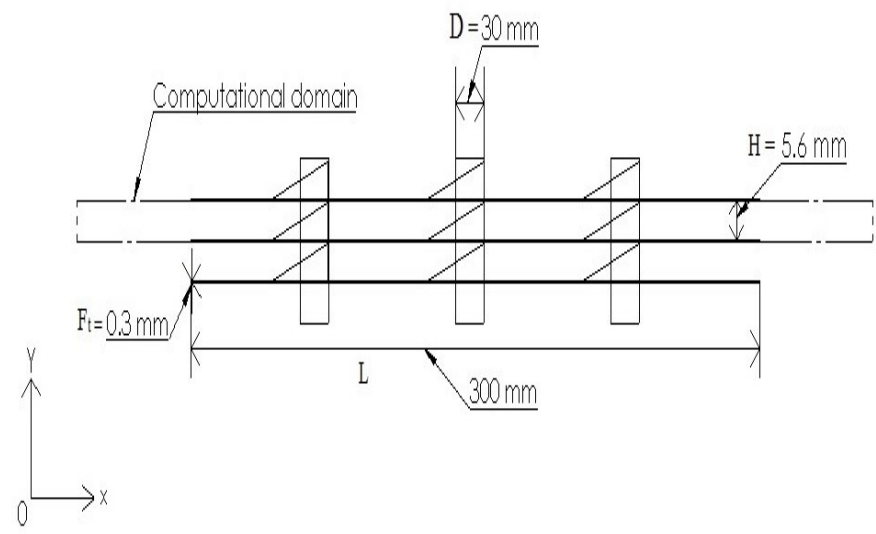

Fig. 4 Side view computational domain.

The following mathematical formulae have been used to study the different parameters in the current work, Torii et al., 2002. The governing equations used are from, Gong et al. (2014).
Mass flow rate $\mathrm{m}: \dot{m}=\rho * A * V$

Where, $\rho=$ density of air at $300 \mathrm{~K}$

Heat transfer rate $\mathrm{q}$ at air side:

$q=\dot{m} * C_{p} *\left(T_{\text {air }, \text { in }}-T_{\text {air, out }}\right)$

Reynolds number: $\operatorname{Re}=\frac{U_{i n} \cdot 2 H}{\gamma}$

Nusselt number: $\mathrm{Nu}=\frac{h_{m} \cdot 2 H}{\lambda}$

Chilton-Colburn factor $(\mathrm{j})$ :

$\mathrm{j}=\frac{N u}{\operatorname{RePr} 1 / 3}$

Fanning friction factor (f):

$\mathrm{f}=\frac{2 H}{4 L}\left\{\frac{\Delta P}{\frac{\rho U_{i n}^{2}}{2}}-\left(K_{C}+K_{e}\right)\right\}$

Governing equations:

Continuity equation

$\frac{\partial}{\partial x_{i}}\left(u_{i}\right)=0$

Momentum equation

$\frac{\partial}{\partial x_{i}}\left(u_{i} u_{k}\right)=\frac{\partial}{\partial x_{i}}\left(\eta \frac{\partial u_{k}}{\partial x_{i}}\right)-\frac{\partial p}{\rho \partial x_{k}}$

Energy equation

$\frac{\partial}{\partial x_{i}}\left(\rho C_{p} u_{i} T\right)=\frac{\partial}{\partial x_{i}}\left(\lambda \frac{\partial T}{\partial x_{i}}\right)$

The numerical model was developed assuming the thermo physical properties of fluid (air) and the fin, DWVG, and tube (aluminum) are constant. The flow is limited to incompressible, laminar and solved for steady condition. The viscous dissipation term is negligible. SIMPLE scheme, Pressure and velocity coupling is used as the iterative algorithm. Pressure based, absolute velocity formulation, steady-state solver is used in FLUENT. The tube surfaces are at constant temperature of $350 \mathrm{~K}$. At the inlet uniform air velocity parallel to the fin is applied at a temperature of $300 \mathrm{~K}$ and pressure outlet condition is used at the downstream. Navier-Stokes and energy equations subjected to afore said boundary conditions is solved. The multi-block hybrid method is adopted to generate the computational grid, and structured grids are preferred where it was feasible. To improve the accuracy of the simulation results, the grids around the tubes and vortex generators are refined.

Table 1 Grid details

\begin{tabular}{|l|l|l|l|l|}
\hline $\begin{array}{l}\text { GRID } \\
\text { NO. }\end{array}$ & $\begin{array}{l}673118 \\
\left(G_{1}\right)\end{array}$ & $\begin{array}{l}895768 \\
\left(G_{2}\right)\end{array}$ & $\begin{array}{l}1073855 \\
\left(G_{3}\right)\end{array}$ & $\begin{array}{l}1211220 \\
\left(G_{4}\right)\end{array}$ \\
\hline NU & 18.78 & 20.35 & 20.29 & 20.67 \\
\hline F & 0.0765 & 0.081 & 0.084 & 0.088 \\
\hline
\end{tabular}

The above problem is solved for plain fin in four different grid numbers ranging from 0.67 to 1.21 million for $\operatorname{Re} 1500$. The details of grid numbers are shown in Table 1. The relative error in Nusselt number for the four different grid numbers is found to be less than $2 \%$. To minimize the computational cost and time $\mathrm{G}_{2}$ is chosen for the present work.

In order to validate the result of the numerical model, simulation is carried out for fin-and-tube heat transfer exchanger without vortex generator (VG) for a range of Reynolds number from 500 to 1500 . The results (j) obtained were compared with the experimental results of Torii et al. (2002) for the same fin tube heat exchanger as shown in Fig. 5. The average deviation was found to be less than $10 \%$.

\section{RESULTS AND DISCUSSIONS}

In the current work, numerical study of fin-tube heat exchanger with DWVGs in 'common-flow up' arrangement has been carried out. The parameters which varied presently are $\alpha$ and l Dw. At first keeping the center of the DWVG fixed, $\alpha$ is varied for $15^{\circ}, 25^{\circ}, 30^{\circ}$ and $35^{\circ}$. The range of angle of attack cannot be increased further due to model 
limitations as further increase will force the winglet's edge out of the computational domain. By keeping the mid-point of the base length of the DWVG constant and fixed and changing the angle of attack also changes the gap (s) between the trailing edges of the DWVG and the tube surface. Varying the gap between the trailing edges of the winglet and the tube, it is expected to create a narrower nozzle-like flow passage and thus, promote higher acceleration to the flowing fluid and eventually remove the zone of poor heat transfer from the near wake of the tubes, Torii et al., (2002).

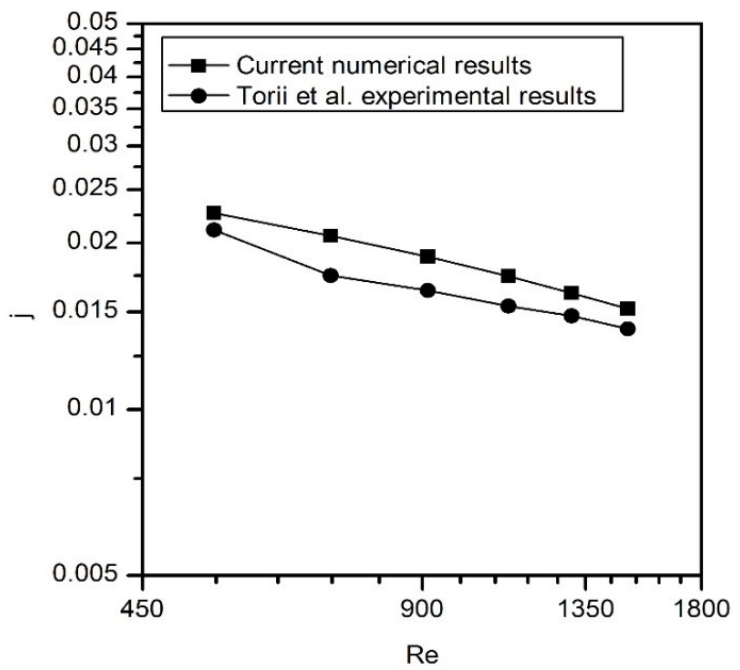

Fig. 5 Comparison of plain fin tube heat exchanger with Torii et al., (2002).

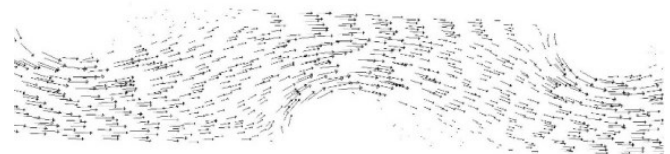

(a) Plain fin, $\mathrm{Re}=\mathbf{5 5 0}$

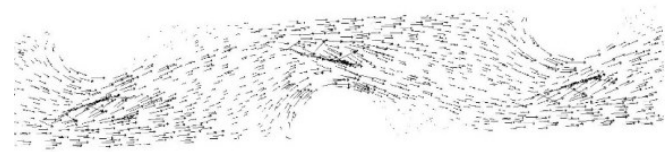

(b) Fin with DWVG, $\operatorname{Re}=550, \alpha=15^{\circ}$

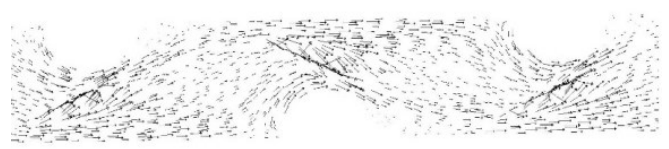

(c) Fin with DWVG, $\operatorname{Re}=550, \alpha=25^{\circ}$

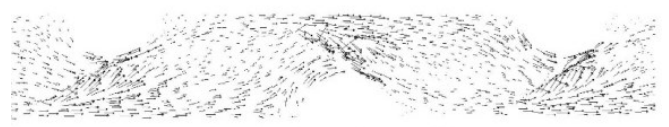

(d) Fin with DWVG, $\operatorname{Re}=550, \alpha=30^{\circ}$

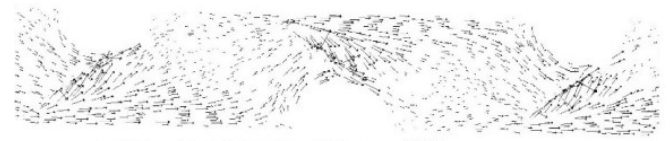

(e) Fin with DWVG, $\operatorname{Re}=550, \alpha=35^{\circ}$

Fig. 6 Velocity vectors at $\mathrm{Re}=550$ of (a) Plain fin, (b) Fin with DWVG having $\alpha=15^{\circ}$, (c) Fin with DWVG having $\alpha=25^{\circ}$, (d) Fin with DWVG having $\alpha=30^{\circ}$, (e) Fin with DWVG having $\alpha=35^{\circ}$.

The details of the velocity vector in all flow configurations are shown in Fig 6. This shows that the fluid flow over the plain fin is more uniform and takes place without much interaction with the heated region of the tubes. While incorporation of DWVG's over the fin experiences additional interaction with the heated region of the tubes and augments generation of vortices. Moreover, it can also be observed that the directional variation of the fluid molecules is increased with the addition of DWVG's. In conclusion we can say that randomization of the fluid molecular movement is large in comparison to plain fin flow pattern. Subsequently, as the angle of attack increases from $15^{\circ}$ to $35^{\circ}$, vortex strength also increases which in turn improves the heat transfer performance, Biswas et al. (1996). The delta winglets disturb the uniform flow greatly which is evident from Fig. 7. Figure 7 (a) and (b) shows a cross view of the flow domain in plain fin and fin with DWVG $\left(\alpha 35^{\circ}\right)$ respectively for a typical Reynolds number 2050. It is very interesting to notice that in case of plain fin the normal to fin surface velocity component are absent, whereas for the case of DWVG these normal velocity components shows a considerable presence. Moreover, Fig. 7 also shows that the maximum instantaneous velocity increased by $42.7 \%$ in case of DWVG's $\left(\operatorname{Re} 2050, \alpha 35^{\circ}\right)$. These normal velocity components are responsible for the higher fluid molecule and fin surface interaction.

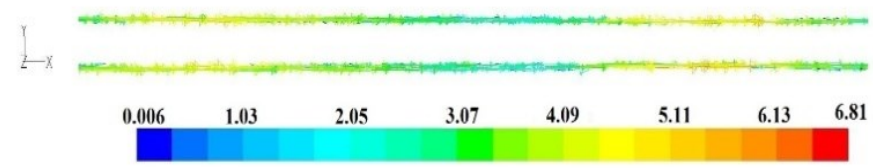

(a)

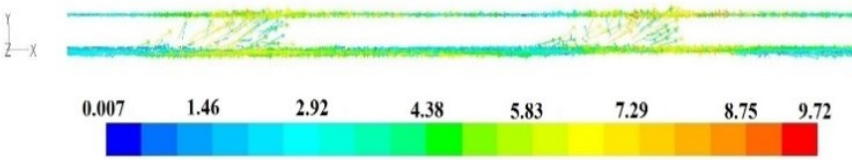

(b)

Fig. 7 Velocity Vectors at $\mathrm{Re}=2050$, (a) Plain Fin, (b) Fin with DWVG having $\alpha=35^{\circ}$

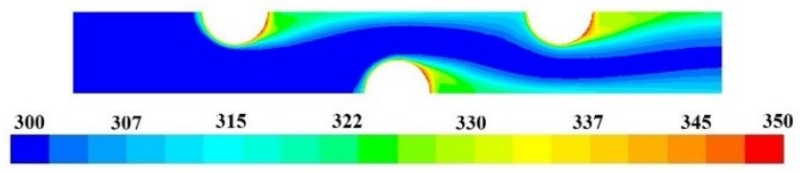

(a) Plain fin without DWVG

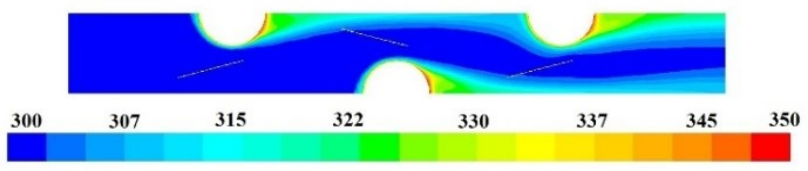

(b) Fin with DWVG, $\alpha=15^{\circ}$

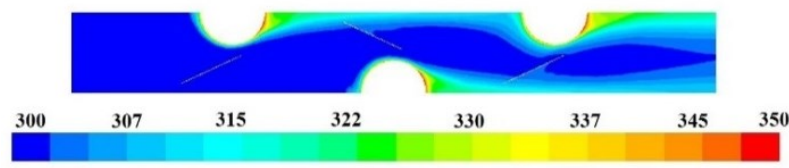

(c) Fin with DWVG, $\alpha=25^{\circ}$

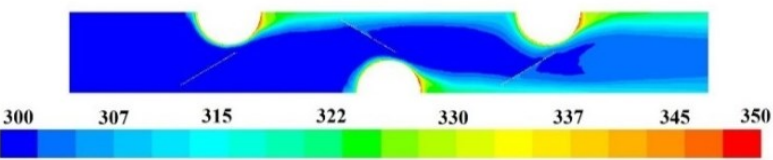

(d) Fin with DWVG, $\alpha=30^{\circ}$

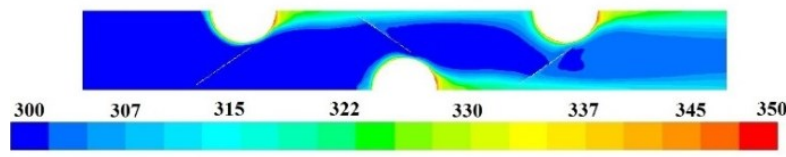

(e) Fin with DWVG, $\alpha=35^{\circ}$

Fig. 8 Temperature Contour at $\mathrm{Re}=550$ of (a) Plain fin without DWVG (b) Fin with DWVG, $\alpha=15^{\circ}$; (c) Fin with DWVG, $\alpha=25^{\circ}$; (d) Fin with DWVG, $\alpha=30^{\circ}$; (e) Fin with DWVG, $\alpha=35^{\circ}$. 
From the temperature contours on the fin surface, Fig. 8, it can be seen that for the same Reynolds number, the DWVG have significant effect on the wake region behind the tubes as compared to plain fin flow pattern. This happens because the winglet directs the fluid towards the tube surfaces and help increase interaction of fluids with the heated surface. The increased inter-molecular interaction of the fluid at fin surface yields rise in average temperature of fin surface as well as the fluid resulting in enhanced heat transfer. Presence of DWVG's promotes dispersion effects and also increases random movement of the fluid particles between two adjacent fins. These flow conditions with enhanced dispersion and random movement of fluid particle enhances the core fluid mixing. This process seems to be accelerated towards the downstream as the flow encounters more DWVG. In due course of the flow, fluid particle interacts with the fin wall with greater frequency and in turn increases the downstream fluid temperature as compared to plain fin heat exchanger.

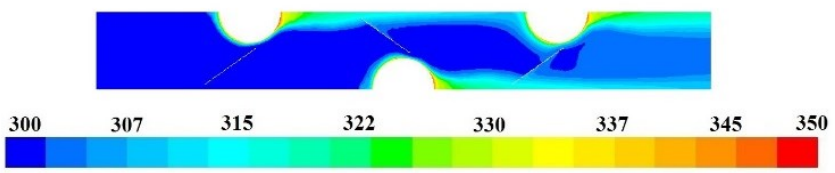

(a) Fin with DWVG, $\alpha=35^{\circ}, \operatorname{Re}=750$

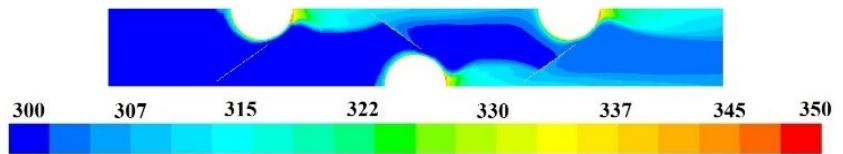

(b) Fin with DWVG, $\alpha=35^{\circ}, \operatorname{Re}=1250$

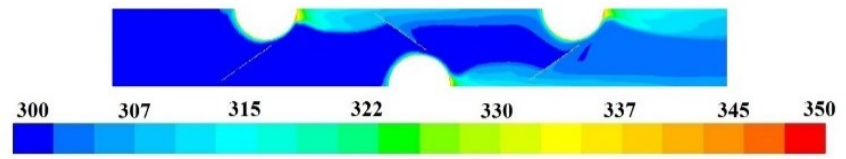

(c) Fin with DWVG, $\alpha=35^{\circ}, \mathrm{Re}=1650$

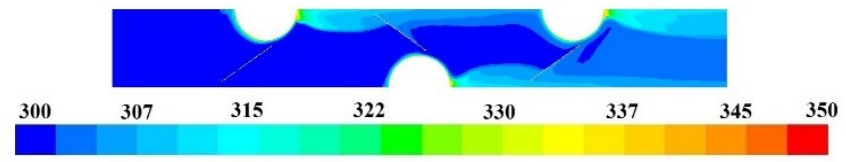

(d) Fin with DWVG, $\alpha=35^{\circ}, \operatorname{Re}=2050$

Fig. 9 Temperature Contour for a typical angle of attack $\alpha=35^{\circ}$ at various Reynolds number shown from (a) to (d).

As the Reynolds number increases, the presence of DWVG's increases the heat transfer even for the same angle of attack. This is due to the greater core fluid mixing and enhanced inter-molecular interaction which is evident from Fig. 9. The results obtained reveal, Fig. 10, the heat transfer coefficient augmented by $6.22 \%, 12.23 \%, 18.59 \%$, and $23.92 \%$ respectively for $\alpha 15^{\circ}, 25^{\circ}, 30^{\circ}$ and $35^{\circ}$ as compared to plain fin. The highest relative increment of $7.25 \%$ in heat transfer was noticed when the angle of attack was incremented from $25^{\circ}$ to $30^{\circ}$.

Also, as the angle of attack was increased from $15^{\circ}$ to $25^{\circ}, 30^{\circ}$, and $35^{\circ}$ the spacing between the trailing edges of the winglets and the tubes reduced from $9 \mathrm{~mm}, 7 \mathrm{~mm}, 5 \mathrm{~mm}$ and $3 \mathrm{~mm}$ respectively. The pressure drop is shown in Fig. 11, reveals an increasing trend with increase in angle of attack. The pressure drop for the angles of $15^{\circ}, 25^{\circ}, 30^{\circ}$ and $35^{\circ}$ increased by $18.06 \%, 31.74 \%, 43.17 \%$ and $53.12 \%$ compared to the plain fin. Now as the spacing decreases the nozzle-like flow passage allows the fluid of very high momentum to remove the zone of poor

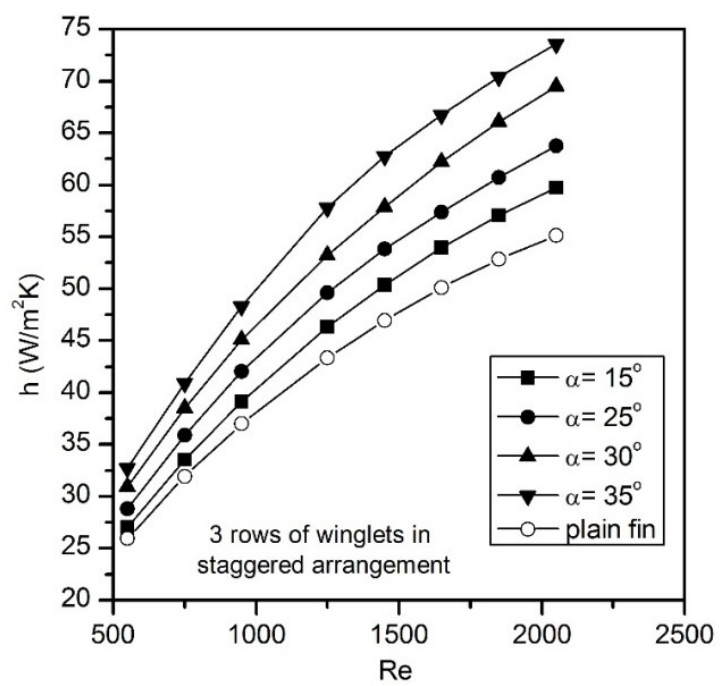

Fig. 10 Variation of heat transfer coefficient vs Re.

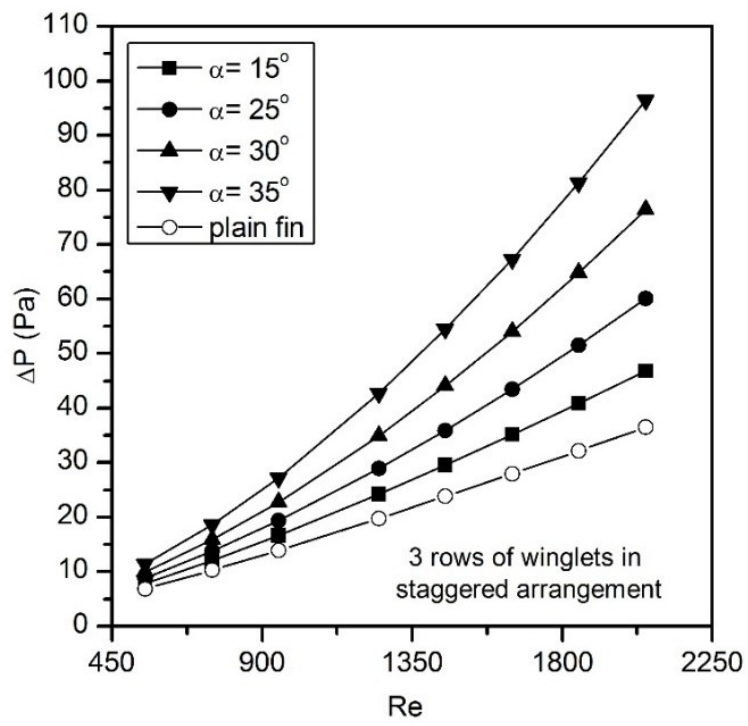

Fig. 11 Variation of Pressure drop vs Re.

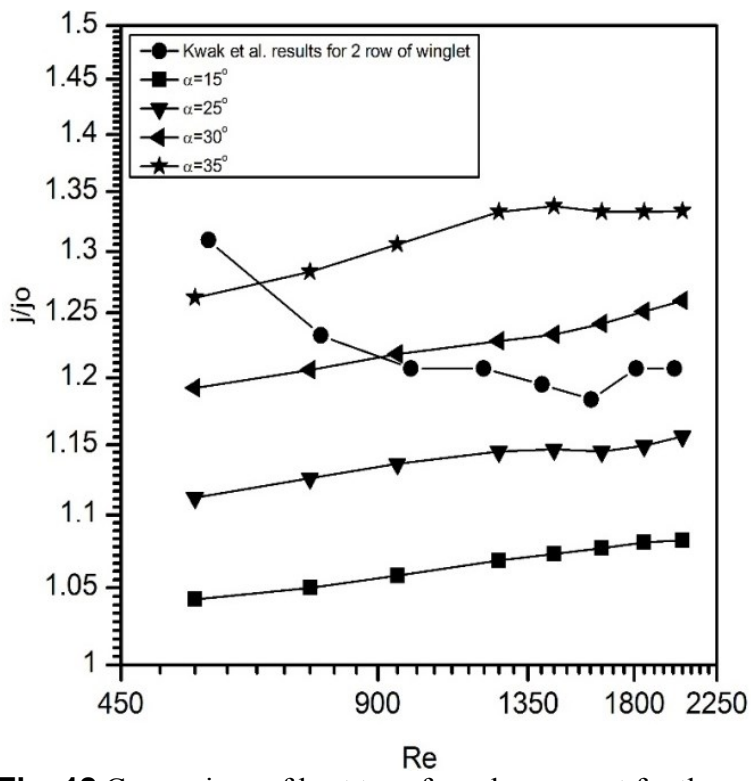

Fig. 12 Comparison of heat transfer enhancement for three rows of winglets with Kwak et al., (2005). 


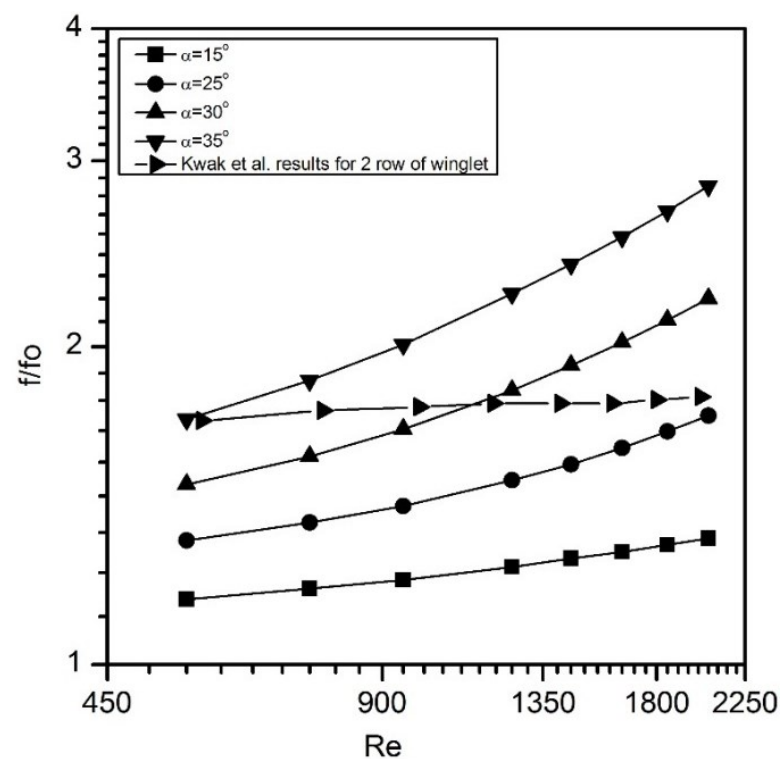

Fig. 13 Comparison of pressure loss penalty for three rows of winglets with Kwak et al., (2005).

The results obtained in Fig. 10, reveals the heat transfer coefficient augmentation by $6.22 \%, 12.23 \%, 18.59 \%$, and $23.92 \%$ respectively for $\alpha 15^{\circ}, 25^{\circ}, 30^{\circ}$ and $35^{\circ}$ as compared to plain fin. The highest relative increment of $7.25 \%$ in heat transfer was noticed when the angle of attack was incremented from $25^{\circ}$ to $30^{\circ}$.

Also, as the angle of attack was increased from $15^{\circ}$ to $25^{\circ}, 30^{\circ}$, and $35^{\circ}$ the spacing between the trailing edges of the winglets and the tubes reduced from $9 \mathrm{~mm}, 7 \mathrm{~mm}, 5 \mathrm{~mm}$ and $3 \mathrm{~mm}$ respectively. The pressure drop is shown in Fig. 11, reveals an increasing trend with increase in angle of attack. The pressure drop for the angles of $15^{\circ}, 25^{\circ}, 30^{\circ}$ and $35^{\circ}$ increased by $18.06 \%, 31.74 \%, 43.17 \%$ and $53.12 \%$ compared to the plain fin. Now as the spacing decreases the nozzle-like flow passage allows the fluid of very high momentum to remove the zone of poor heat transfer from the rear of the tubes. But as the distance decreases the winglets are more prone to be heated from the high temperatures of the tube surfaces and thus, itself act as a heated surface. And hence taking into account the pressure drop, the distance and an increment of heat transfer from the previous angle, the angle of attack of $30^{\circ}$ is best suited for further analysis. Figure 12 and 13 shows the comparison of current work with the work of Kwak et al., (2005), which was based on using two rows of winglets as compared to current work of using three rows of winglets in staggered arrangement. The heat transfer enhancement increases significantly with three rows of winglets as the wake region is affected and the zone of poor heat transfer decreases behind all the three rows of the tubes.

The final parameter of study is the base length of the DWVG as it also plays a vital role in defining the strength of the vortices of such flow. The angle of attack is kept at $30^{\circ}$, and the gap between the trailing edges and the tube is $5 \mathrm{~mm}$, while the central angle is kept fixed at $110^{\circ}$. The base length is changed by keeping trailing edge fixed at $\mathrm{R}$ as shown in Fig. 3. Three different winglet lengths viz. $20 \mathrm{~mm}, 30 \mathrm{~mm}$, and $35 \mathrm{~mm}$ are chosen to see the effect on flow properties as literature also has very few data of such variation.

The change in the base length of the DWVG shows that if the base length is decreased the pressure drop decreases significantly. Figure 14 shows the effect of DW length on pressure drop, when compared with all cases including plain fin it was observed that decrease in base length reduces the pressure drop penalty but heat transfer also decreases slightly. When the base length decreases from $35 \mathrm{~mm}$ to $30 \mathrm{~mm}$ and $20 \mathrm{~mm}$, the pressure drop decrease from $40.51 \%$ to $37.98 \%$ and $29.44 \%$ as compared to plain fin.

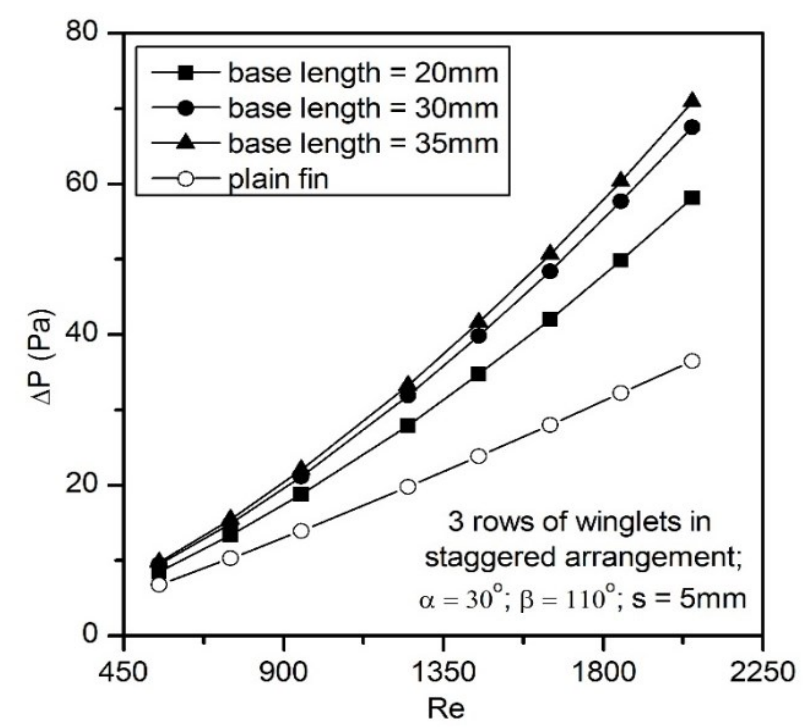

Fig. 14 Variation of Pressure drop vs Re

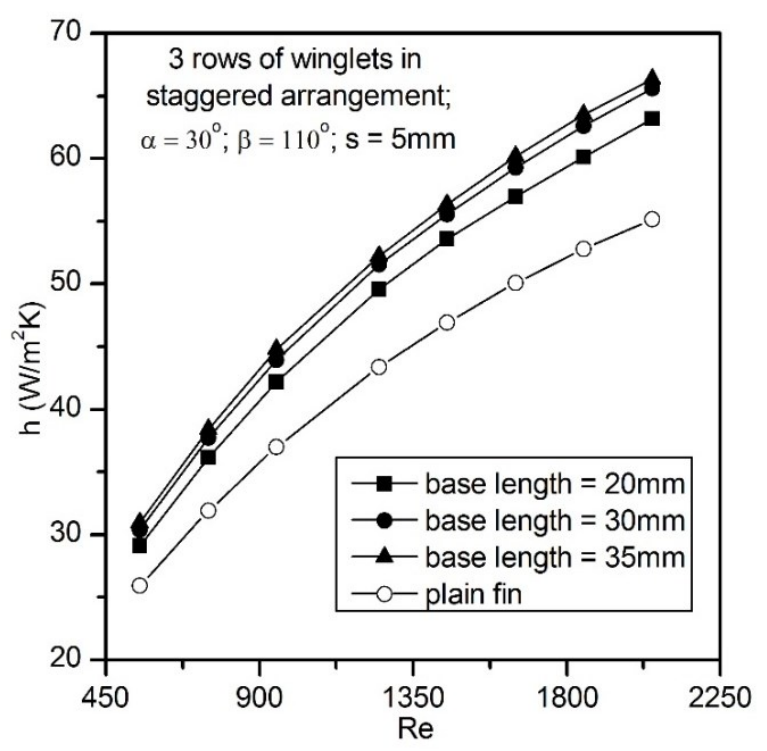

Fig. 15 Variation of heat transfer coefficient vs Re

The heat transfer on the other hand also shows decrement with decrease in length of the DWVG as shown in the Fig. 15. The heat transfer coefficient decreased by $16.8 \%, 15.5 \%$ and $12.1 \%$ for base length $35 \mathrm{~mm}$, $30 \mathrm{~mm}$ and $20 \mathrm{~mm}$ respectively when compared to plain fin. Figure 16 and 17 also further verify the same results and thus signify that as the length of the winglet increases, the winglets become a longer obstruction and decelerate the flow towards the next consecutive winglets, which is the reason of enhanced heat transfer, Kwak et al., 2005. Although a further increment in length will further help improve the heat transfer but at the cost of higher pressure drop penalty, which is undesirable as a higher pressure drop will require more energy for the flow to take place. The pressure drop was much lower for the case of length of $20 \mathrm{~mm}$ and had a relative similar heat transfer as compared to the case of winglet with base length of $30 \mathrm{~mm}$, and thus, it helps improve the economical factor of the winglet, that a smaller winglet can be used for a better heat transfer and at a relative lower pressure drop. 


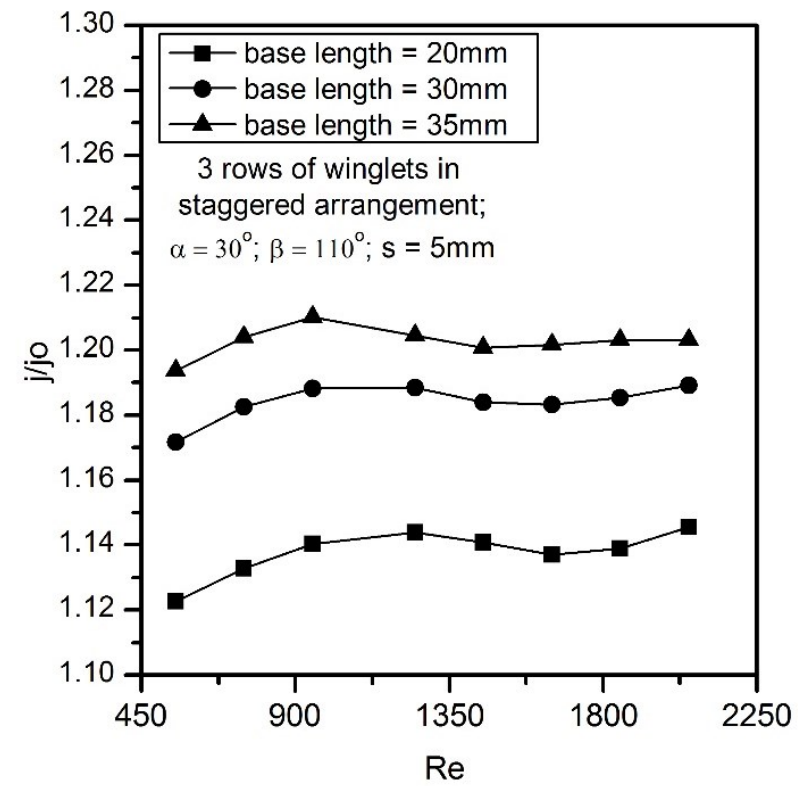

Fig. 16 Variation of $\mathrm{j} / \mathrm{jo}$-factor vs Re

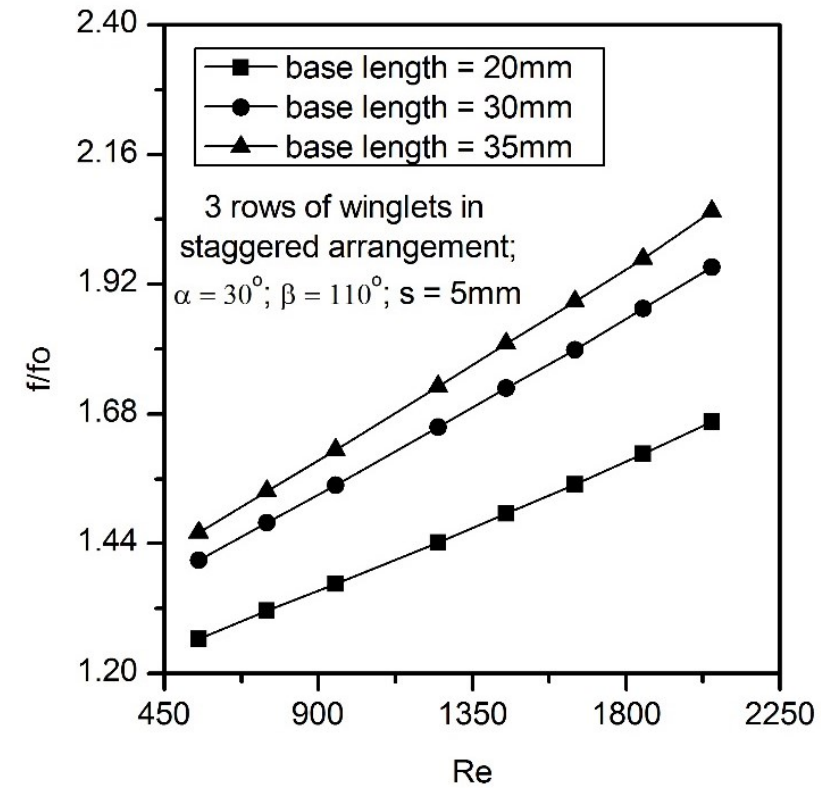

Fig. 17 Variation of f/fo-factor vs Re

\section{CONCLUSIONS}

1. The heat transfer coefficient increased by $6.22 \%, 12.23 \%, 18.59 \%$, and $23.92 \%$ respectively for the angle of attack of $15^{\circ}, 25^{\circ}, 30^{\circ}$ and $35^{\circ}$ respectively as compared to plain fin. The highest relative increment of $7.25 \%$ in heat transfer was noticed when the angle of attack was incremented from $25^{\circ}$ to $30^{\circ}$.

2. The pressure drop penalty for the angles of $15^{\circ}, 25^{\circ}, 30^{\circ}$ and $35^{\circ}$ increased by $18.06 \%, 31.74 \%, 43.17 \%$ and $53.12 \%$ compared to the plain fin. But the overall thermos-fluidic performance increases with the incorporation of three row DWVG's.

3. As the distance between the trailing edge of the winglet with respect to the tube surface decreases winglets are more prone to be heated from the high temperatures of the tube surfaces and thus contributes in enhancement of heat transfer.

4. The variation in the base length of the DWVG shows that if the base length is decreased the pressure drop decreases significantly, as compared to the cases with higher base lengths, but the heat transfer on the other hand increases with the increase in length.

\section{ACKNOWLEDGEMENTS}

The authors express their gratitude for the facility, help and support received from Department of Mechanical Engineering, NIT Agartala and MHRD, GOI for financial support.

\section{NOMENCLATURE}

$\mathrm{Cp} \quad$ Coefficient of pressure

f Fanning friction factor

$\mathrm{H} \quad$ Channel height (fin pitch) (mm)

$\mathrm{h} \quad$ Heat transfer coefficient $\left(\mathrm{W} / \mathrm{m}^{2} \mathrm{~K}\right)$; height of the winglet $(\mathrm{mm})$

j Chilton-Colburn factor

$\mathrm{K}_{\mathrm{c}} \quad$ Contraction coefficient

$K_{e} \quad$ Expansion coefficient

lDw Base length of winglet of DWVG(mm)

$\dot{m} \quad$ Mass flow rate $(\mathrm{kg} / \mathrm{s})$

$\mathrm{Nu} \quad$ Nusselt number

Pr Prandlt number

Re Reynolds number

$\mathrm{s} \quad$ Spanwise gap between the trailing edge of winglet and thesurface of tube DWVG (mm)

$\mathrm{S}_{1} \quad$ Streamwise pitch

$\mathrm{S}_{2} \quad$ Spanwise pitch

$\mathrm{T}_{\mathrm{air}}$ in Inlet temperature of air $(\mathrm{K})$

$\mathrm{T}_{\text {air, out }} \quad$ Outlet temperature of air $(\mathrm{K})$

$U_{\text {in }} \quad$ Velocity of air at the inlet

$\mathrm{u}$ component of velocity vector

$\Delta \mathrm{P} \quad$ Pressure drop $(\mathrm{Pa})$

Greek Symbols

$\alpha \quad$ attack angle of winglet of DWVG (deg)

$\beta \quad$ central angle from the front stagnation point of tube of DWVG (deg)

$\rho \quad$ density of air $\left(\mathrm{kg} / \mathrm{m}^{3}\right)$

$\eta \quad$ viscosity (Pa s)

$\lambda$ thermal conductivity $(\mathrm{W} / \mathrm{mK})$

Subscript

c contraction

DW delta winglet

e expansion

$\mathrm{p} \quad$ pressure

in inlet

out outlet

o plain fin

$\mathrm{k} \quad$ integer

\section{NOMENCLATURE}

$C \quad$ heat capacity $\left(\mathrm{J} / \mathrm{m}^{3} \cdot \mathrm{K}\right)$

$c_{p} \quad$ specific heat $(\mathrm{J} / \mathrm{kg} \cdot \mathrm{K})$

$h \quad$ latent heat of phase change $(\mathrm{J} / \mathrm{kg})$

$k \quad$ thermal conductivity $(\mathrm{W} / \mathrm{m} \cdot \mathrm{K})$

$M \quad$ molar mass $(\mathrm{kg} / \mathrm{kmol})$

$q^{\prime \prime} \quad$ heat flux $\left(\mathrm{W} / \mathrm{m}^{2}\right)$

$R \quad$ reflectivity

$R_{g} \quad$ specific gas constant $(\mathrm{J} / \mathrm{kg} \cdot \mathrm{K})$

$t \quad$ time (s)

$T \quad$ temperature (K)

$u \quad$ interfacial velocity $(\mathrm{m} / \mathrm{s})$

$x \quad$ coordinate $(\mathrm{m})$ 


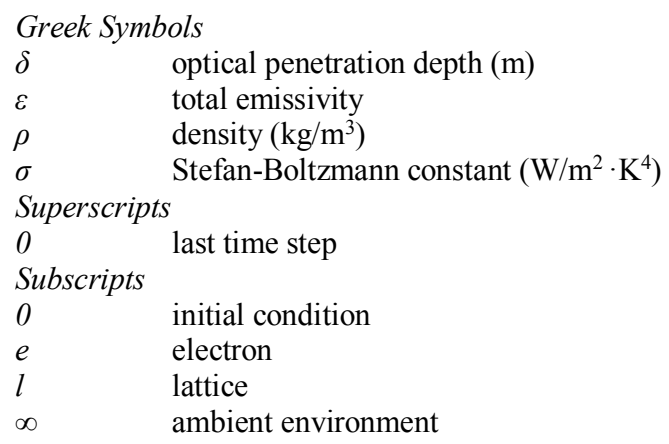

\section{REFERENCES}

Allison, C.B. and Dally, B.B., 2007, "Effect of a Delta-Winglet Vortex Pair on the Performance of a Tube-Fin Heat Exchanger," Int. J. Heat and Mass Transfer, 50, 5065-5072.

http://dx.doi.org/10.1016/i.iiheatmasstransfer.2007.08.0Q3

Biswas, G., Torii, K., Fujii, D., Nishino, K., 1996, "Numerical and Experimental Determination of Flow Structure and Heat Transfer Effects of Longitudinal Vortices in a Channel Flow, "International Journal of Heat and Mass Transfer, 39(16) 3441-3451

http://dx.doi.org/10.1016/0017-9310(95)00398-3

Biswas, G., and Chattopadhyay, H.,1992, "Heat Transfer in a Channel with Built-In Wing-Type Vortex Generators," International Journal of Heat and Mass Transfer, 35, 803-814.

http://dx.doi.org/10.1016/0017-9310(92)90248-0.

Chen, Y., Fiebig, M., Mitra, N.K., 2000,"Heat Transfer Enhancement of Finned Oval Tubes with Staggered Punched Longitudinal Vortex Generators,"Int. J. Heat Mass Transf., 43(3), 417-435. http://dx.doi.org/10.1016/S0017-9310(99)00157-X.

Chu, P., He, L., Tao, W.Q., 2009,“'Three-Dimensional Numerical Study of Flow and Heat Transfer Enhancement Using Vortex Generators in Fin-and-Tube Heat Exchangers," J. Heat Transfer, 131(9), 09190310919039.

http://dx.doi.org/10.1115/1.3139185.

Delac, B., Trp, A., Lenic, K., 2014, "Numerical Investigation of Heat Transfer Enhancement in a Fin and Tube Heat Exchanger using Vortex Generators," Int. J. Heat Mass Transfer, 78, 662-669.

http://dx.doi.org/10.1016/uiheatmasstransfer.2014.07.027

Edwards, F.J. and Alker, G.J.R., 1974, “The Improvement of Forced Convection Surface Heat Transfer using Surface Protrusions in the Form of (A) Cubes and (B) Vortex Generators," Proceedings of the Fifth International Heat Transfer Conference Tokyo, 2, 2244-2248.

Eibeck, P.A. and Eaton, J.K., 1987, "Heat Transfer Effects of a Longitudinal Vortex Embedded in a Turbulent Boundary Layer," J. Heat Transf., 109, 16-24.

http://dx.doi.org/10.1115/1.3248039.

Fiebig, M., Kallweit, P., Mitra, N., Tiggelbeck, S., 1991, "Heat Transfer Enhancement and Drag by Longitudinal Vortex Generators in Channel Flow," Experimental Thermal and Fluid Science, 4(1), 103-114. http://dx.doi.org/10.1016/0894-1777(91)90024-L.

Gong, B., Wang, L., Lin, Z., 2014, "Heat Transfer Characteristics of a Circular Tube Bank Fin Heat Exchanger with Fins Punched Curve Rectangular Vortex Generators in the Wake Regions of the Tubes," Applied Thermal Engineering, 75, 224-238. http://dx.doi.org/10.1016/j.applthermaleng.2014.09.043

He, Y.L., Han, H., Tao, W, Zhang, Y., 2012, "Numerical Study of HeatTransfer Enhancement by Punched Winglet-TypeVortex Generator Arrays in Fin-And-Tube Heat Exchangers," International Journal of Heat and Mass Transfer, 55, 5449-5458.

http://dx.doi.org/10.1016/i.iiheatmasstransfer.2012.04.059

He, J., Liu, L., Jacobi, A.M, 2010,“Air-Side Heat-Transfer Enhancement by a New Winglet Type Vortex Generator Array in a Plain-Fin RoundTube Heat Exchanger," Trans. ASME132.

http://dx.doi.org/10.1115/1.4000988.

Joardar, A. and Jacobi A.M., 2007, “A Numerical Study of Flow and Heat Transfer Enhancement using an Array of Delta-Winglet Vortex Generators in a Fin-And Tube Heat Exchanger," J. Heat Transfer, 129, 1156-1167.

http://dx.doi.org/10.1115/1.2740308.

Joardar, A. and Jacobi A.M., 2008,"Heat Transfer Enhancement by Winglet-Type Vortex Generator Arrays in Compact Plain-Fin-And-Tube Heat Exchangers," Int. J. Refrig, 31, 87-97. http://dx.doi.org /10.1016/i.iirefrig.2007.04.011.

Katoaka, K. Doi, H., Komai, T., 1977, "Heat/Mass Transfer in Taylor Vortex Flow with Constant Axial Flow Rates, "International Journal of Heat and Mass Transfer, 20(1), 57-63.

http://dx.doi.org/10.1016/0017-9310(77)90084-9.

Kwak, K. M., Torii, K., Nishino, K., 2005,“Simultaneous Heat Transfer Enhancement and Pressure Loss Reduction for Finned-Tube Bundles with the First Or Two Transverse Rows of Built-In Winglets, "Experimental Thermal and Fluid Science, 29(5), 625-632. http://dx.doi.org/10.1016/i.expthermflusci.2004.08.005.

Leu, J.S. Wu, Y., Jang, J., 2004, "Heat Transfer and Fluid Flow Analysis in Plate-Fin and Tube Heat Exchangers with a Pair of Block Shape Vortex Generators," Int. J. Heat Mass Transfer, 47, 4327-4338. http://dx.doi.org/10.1016/j.ijheatmasstransfer.2004.04.031.

Mehta, R.D. and P. Bradshaw,1988, "Longitudinal Vortices Imbedded in Turbulent Boundary Layer: Part 2 Vortex Pair with Common Flow Upwards,"J. Fluid Mech., 188, 529-546.

http://dx.doi.org/10.1017/S002211208800Q837.

Pauley,W.R. and Eaton, J.K.,1988, "The Fluid Dynamics and Heat Transfer Effects of Streamwise Vortices Embedded in a Turbulent Boundary Layer," Report No. MD- 51, Department of Mechanical Engineering, Stanford University.

Pesteei, S.M., Subbarao, P.M.V., Agarwal, R.S., 2005, "Experimental Study of the Effect of Winglet Location on Heat Transfer Enhancement and Pressure Drop in Fin-Tube Heat Exchangers," Applied Thermal Engineering, 25, 1684-1696.

http://dx.doi.org/10.1016/i.applthermaleng.2004.10.013.

Schubauer, G.B, and Spangenberg, W.G,1960, "Forced Mixing in Boundary Layers," J. Fluid Mech., 8, 10-31.

http://dx.doi.org/10.1017/S0022112060000372.

Sedney, R.,1973, "A Survey of the Effects of the Small Protuberances on Boundary-Layer Flows," AIAA J., 11, 782-792.

http://dx.doi.org/10.2514/3.50520. 
Sinha, A., Raman, K.A., Chattopadhyay, H., Biswas, G. 2013,"Effects of Different Orientations of Winglet Arrays on The Performance Of PlateFin Heat Exchangers," Int. J.Heat and Mass Transfer, 7(1), 202-214. http://dx.doi.org/10.1016/i.iiheatmasstransfer.2012.10.034.

Tigglebeck, St., Mitra, N.K., Fiebig, M., 1994, "Comparison of Wing Type Vortex Generators for Heat Transfer Enhancement in Channel Flow," J. Heat Transf., 116(4), 880-885.

http://dx.doi.org/10.1115/1.2911462

Tiwari, S., Maurya, D., Biswas, G., Eswaran, V.,2003,"Heat Transfer Enhancement in Cross-Flow Heat Exchangers using Oval Tubes and Multiple Delta Winglets," Int. J. Heat and Mass Transfer, 46(15), 28412856.

http://dx.doi.org/10.1016/S0017-9310(03)00047-4.

Torii, K., Kwak, K.M., Nishino, K., 2002,“Heat Transfer Enhancement Accompanying Pressure-Loss Reduction with Winglet-Type Vortex Generators for Fin-Tube Heat Exchangers," Int. J. of Heat and Mass Transfer, 45(18), 3795-3801.

http://dx.doi.org/10.1016/S0017-9310(02)00080-7.
Torii, K., Kwak, K.M., Nishino, K., 2003, "Heat Transfer and Pressure Loss Penalty for the Number of Tube Rows of Staggered Finned-Tube Bundles with A Single Transverse Row of Winglets," Int. J. of Heat and Mass Transfer, 46 (1), 175-180. http://dx.doi.org/10.1016/S0017-9310(02)00235-1

Wang, C.C., Lo, J., Lin, Y.T., Wei, C.S.,2002,"Flow Visualization of Annular and Delta Winglet Vortex Generators in Fin-And-Tube Heat Exchanger Application," Int. J. Heat Mass Transfer, 45(18), 3803-3815 http://dx.doi.org/10.1016/S0017-9310(02)00085-6.

Wu, J.M., Tao, W.Q., 2011, “Impact Of Delta Winglet Vortex Generators on the Performance of A Novel Fin-Tube Surfaces with Two Rows of Tubes in Different Diameters," Energy Conversion and Management, 52(8),2895-2901. http://dx.doi.org/10.1016/i.enconman.2011.03.002.

Yang, J.S., Lee, D.W., Choi, G.M., 2008, "Numerical Investigation of Fluid Flow and Heat Transfer Characteristics by Common-Flow-Up," Int. J. Heat and Mass Transfer, 51(25),6332-6336.

http://dx.doi.org/10.1016/uiheatmasstransfer.2008.07.001. 